\title{
Tempo e Trânsito na Experiência Subjetiva de Motoristas
}

Time and Traffic on the Subjective Experience of Drivers

Tiempo y Tránsito en la Experiencia Subjetiva de Conductores

Ana Inez Oka Elvas de Lima \&

Sylvia Cavalcante

Universidade de Fortaleza

http://dx.doi.org/10.1590/1982-3703000412013 
Resumo: Esta pesquisa investiga como são percebidos e vivenciados o tempo e a pressa no trânsito por motoristas de Fortaleza, identificando e analisando seus estados subjetivos e comportamentos associados a essa experiência. Para a coleta de dados, organizaram-se quatro grupos focais, a partir dos quais emergiram diversos elementos relacionados ao tempo e à pressa e à incidência de comportamentos inadequados no trânsito, segundo o sexo e a idade dos participantes. Para analisar os dados obtidos nas discussões grupais utilizaram-se os critérios da Análise Clássica de Conteúdo. Os resultados levaram à conclusão de que a questão do tempo e da pressa constitui um potencial gerador de erros e violações na condução de veículos, pois exerce influência decisiva sobre os comportamentos dos motoristas e configura uma realidade importante para se compreender os fatores humanos envolvidos na dinâmica do trânsito e do ambiente urbano como um todo.

Palavras-chave: Tempo. Trânsito. Subjetividade. Violações no trânsito.

Abstract: This research investigates how time and haste are perceived and lived by drivers in the traffic of Fortaleza, Ceara state, Brazil, identifying and analyzing their subjective states and behaviors associated with this experience. Data was collected through the analysis of four Focal Groups, from which emerged several elements related to time and haste and to the incidence of inadequate traffic behaviors, according to participant's gender and age. The criteria of Classic Content Analysis were used to analyze the data obtained in the group discussions. The results led to the conclusion that the matter of time and haste constitutes a potential generator of errors and violations on the conduction of vehicles, because it substantially influences the behaviors of drivers and it configures an important reality to comprehend the factors involved in the traffic dynamics and in the urban environment as a whole.

Keywords: Time. Traffic. Subjectivity. Traffic violations.

Resumen: Esta investigación indaga la forma en que se percibe y se experimenta el tiempo y la prisa en el tránsito de los conductores de Fortaleza, identificando y analizando los estados subjetivos y conductas asociadas con esa experiencia. Para la recolección de datos, se organizaron cuatro Grupos Focales, de los que surgieron varios elementos relacionados al tiempo, a la prisa y a la incidencia de conductas inapropiadas en el tránsito, según el sexo y la edad de los participantes. Para analizar los datos obtenidos en los grupos de discusión, se utilizaron los criterios del análisis Clásico de Contenido. Los resultados Ilevaron a la conclusión de que la cuestión del tiempo y la prisa es un potencial generador de errores e infracciones en la conducción de vehículos, debido a que ejerce influencia sobre el comportamiento de los conductores y configura una realidad importante para entender los factores humanos implicados en la dinámica del tránsito y del entorno urbano en su conjunto.

Palabras-clave: Tiempo. Tránsito. Subjetividad. Infracciones de tránsito.

Questões voltadas à qualidade e aos estilos de vida urbanos se mostram, hoje, especialmente relevantes considerando-se as diversas circunstâncias que afetam a integração e o bem-estar dos habitantes das grandes cidades, o que inclui a aceleração do ritmo cotidiano, que parece marcar fortemente a vida na atualidade. Milton Santos (2002, p. 21) comenta esse aspecto da realidade ao afirmar que "Este momento no qual vivemos, para repetir Chesneaux, é de uma sociedade sincrônica, integral, na qual o homem vive sob a obsessão do tempo, sociedade essa que é, ao mesmo tempo, cronofágica".
A falta de tempo, seja para a realização das tarefas diárias, para a convivência entre as pessoas ou para o lazer, aparece como uma questão cada vez mais emblemática, assumindo inegável importância no cenário contemporâneo. Vários trabalhos constatam que o ritmo de vida acelerado da atualidade também é fator causador de estresse, tornando-se responsável pelo surgimento de várias doenças (Folkman, 1984; Lazarus \& Folkman, 1984).

A realização das diversas atividades da vida moderna, por sua vez, implica constantes deslocamentos e, portanto, mobilidade no 
espaço urbano, tema que acaba por remeter à noção de trânsito. Para se abordar o assunto, tomou-se como referência uma conceituação mais ampla do termo, indicada nas Diretrizes para a Política Nacional de Trânsito (Brasil, 2004, p. 5):

O direito de todos os cidadãos de ir e vir, de ocupar o espaço público e de conviver socialmente nesse espaço são princípios fundamentais para compreender a dimensão do significado expresso na palavra trânsito. Tal abordagem, ampliando a visão sobre o trânsito, considera-o como um processo histórico-social que envolve, principalmente, as relações estabelecidas entre as pessoas e o espaço, assim como as relações das pessoas entre si.

Estudos como o de Mello (1998) apontam que o automóvel redimensionou as distâncias, reconfigurou os espaços em função das possibilidades de deslocamento e introduziu nova noção de tempo. Rozestraten (1988) já havia concebido o sistema de trânsito como constituído de vários subsistemas, com destaque para o indivíduo, a via e o veículo, o primeiro constituindo o mais complexo em razão dos muitos fatores envolvidos e apresentando probabilidade de desorganizar o sistema como um todo.

Com efeito, impõe-se aos condutores um desgaste adicional para realizar suas atividades cotidianas em face das circunstâncias negativas que marcam o ambiente do trânsito, refletindo, inclusive, na questão do tempo disponível. Emerge nesse contexto, assim, a relação entre espaço e tempo.

Referindo-se a essa relação, Santos (2002) observa que os indivíduos não detêm o mesmo comando do tempo nas cidades, porque o espaço aparece como coordenador das diversas organizações do tempo, e infere que o espaço é tempo. Como forma de dar conta da velocidade que lhe é exigida nas diversas dimensões de sua existência, o indivíduo parece viver em função de ritmos cada vez mais acelerados, todavia a realidade do trânsito e da mobilidade urbana se revela como elemento problemático, pois frequentemente deixa de atender à sua função precípua de possibilitar e agilizar o movimento e a apropriação dos espaços, transformando-se, ironicamente, com frequência, numa experiência de restrição de mobilidade e de perda de tempo.

É o que demonstra a pesquisa realizada pelo Instituto de Pesquisas Econômicas Aplicadas (Ipea)/Associação Nacional de Transportes Públicos (ANTP) em 1998, intitulada Redução das deseconomias urbanas com a melhoria do transporte público, que estimou os gastos com congestionamentos em dez capitais brasileiras, apontando a cifra de 5 bilhões de reais a cada ano, sendo que 120 milhões de horas são perdidas pelos usuários de transportes coletivos.

Assim, o indivíduo, nos seus trajetos cotidianos, se acha impossibilitado de avançar, veloz, no trânsito e evitar os congestionamentos e outras barreiras à sua livre mobilidade. O Ministério das Cidades, ao implantar o programa brasileiro de acessibilidade urbana Brasil acessível, em 2004, reconheceu a existência de uma crise de mobilidade que engloba as questões transporte público e trânsito.

O crescimento progressivo da cidade de Fortaleza, Ceará, Brasil, indicado também pelo aumento significativo da população, que ascendeu de 1.768.637, em 1991, para 2.452.185, em 2010 (IBGE, 2010), tem levado um número crescente de condutores e veículos às vias públicas. Dados fornecidos pelo Departamento Estadual de Trânsito do Ceará (DETRAN-CE, 2010) informam que a frota de veículos da região metropolitana triplicou entre $1991 \mathrm{e}$ 2010, passando de 224.065 para 707.731, o que tem gerado intensos congestionamentos e afetado sobremaneira a mobilidade dos cidadãos fortalezenses.

Destacam-se, nesse contexto, as proporções alarmantes de ocorrência de acidentes fatais, cujos índices colocam o Brasil em uma das posições de liderança no panorama mundial, alcançando, segundo dados das Diretrizes para a Política Nacional de Trânsito (Brasil, 2004), 350 mil acidentes anuais com vítimas no país, dos quais resultam cerca de $30 \mathrm{mil}$ mortes e 300 mil feridos.

Macêdo (2004) observa que suposições, hipóteses e indícios técnicos nos levam a identificar os fatores humanos como principais responsáveis pelos acidentes de trânsito, 
indicando estudos como o do Detran de São Paulo, o qual aponta que $90 \%$ dos acidentes ocorrem porque o motorista comete erros, para ilustrar sua assertiva.

Rozestraten (1988) considerava a pressa condição ou estado de natureza mental ou emocional - causa humana indireta para a ocorrência de acidentes. Assim, para o autor, o estar apressado é um dos estados emocionais que podem influenciar o comportamento dos condutores de veículos.

Pouco ainda se conhece acerca de variáveis antecedentes de comportamentos inadequados de motoristas no Brasil, dada a escassa literatura na área, mas estudos com amostras brasileiras como os de Monteiro (2004) e Macêdo (2004) têm sido produzidos com o objetivo de dar a conhecer melhor o componente humano no trânsito, que afeta a condução e favorece ou ocasiona erros e violações no trânsito, relacionados, em vários estudos, à ocorrência de acidentes.

Monteiro (2004) e Macêdo (2004) apontam a existência de distinções entre os comportamentos de motoristas mais jovens e mais velhos e de motoristas homens e mulheres. Com efeito, observar os fenômenos do trânsito e os condutores de veículos a partir dessas variáveis individuais, tais como gênero e idade, pode se mostrar de especial relevância para se retratar o perfil dos condutores e conhecer melhor o objeto de estudo escolhido.

A pesquisa em comento buscou investigar o modo como é vivenciada a questão do tempo e da pressa no trânsito, visando identificar comportamentos e estados subjetivos de motoristas de Fortaleza associados a essa experiência e sua relação com a incidência de ações inadequadas na condução de veículos.

\section{Método}

O procedimento adotado neste trabalho para a coleta de dado foi um dos sugeridos por Günther (2004, p. 9) quando apontou aproximações básicas necessárias à compreensão dos comportamentos e os estados subjetivos nas Ciências Sociais, que consiste em "perguntar às pessoas sobre o seu comportamento: o que fazem (fizeram) e seus estados subjetivos: o que, por exemplo, pensam (pensaram)". Assim, os sentimentos e comportamentos apontados neste trabalho foram evocados em relatos feitos pelos próprios motoristas.

\section{Instrumentos}

Para se atingir o objetivo proposto na pesquisa, utilizou-se como recurso metodológico uma técnica essencialmente qualitativa: o grupo focal. A técnica utilizada, como ressaltam Espinosa, Díaz e Aravena (1999), consiste na formação de grupos, no âmbito dos quais o investigador provoca a conversação e objetiva articular distintas perspectivas mediante $\mathrm{o}$ emprego de uma linguagem comum. Como esclarece Carlini-Cotrim (1996), a essência das entrevistas coletivas, a exemplo dos grupos focais, consiste na interação entre seus participantes, considerando que a experiência de troca faz emergirem novas opiniões, enriquecendo os dados por intermédio da estimulação recíproca dos integrantes.

Nesse sentido, no dizer de Gaskell (2002, p. 65):

A entrevista qualitativa fornece os dados básicos
para o desenvolvimento e a compreensão
das relações entre os atores sociais e sua
situação. O objetivo é uma compreensão
detalhada das crenças, atitudes, valores e
motivações em relação aos comportamentos
das pessoas em contextos sociais específicos.

\section{Participantes}

Tendo como referência os estudos de Monteiro (2004) e Macêdo (2004), trabalhou-se nesta pesquisa com grupos femininos e masculinos de motoristas, separados, ainda, em grupos de indivíduos mais jovens e mais velhos, em igual proporção. Os participantes foram recrutados dentre os diversos frequentadores do campus da Universidade de Fortaleza (Unifor), oriundos de vários bairros da cidade, com base na faixa de idade e no gênero como critérios de homogeneidade. Eles atenderam às condições: possuir carteira de habilitação para dirigir veículos automotores e dirigir habitualmente pela cidade de Fortaleza, em carro próprio ou da família. 
Após aceitarem participar da pesquisa, os participantes assinaram o Termo de Consentimento Livre Esclarecido, submetido ao Comitê de Ética em Pesquisa da Universidade de Fortaleza.

Organizaram-se dois grupos masculinos de motoristas, cada um com seis integrantes, um deles com participantes mais jovens (com idade entre 18 e 29 anos) e outro composto de homens mais velhos (com idade acima de 30 anos). Formaram-se, ainda, dois grupos de motoristas mulheres, cada um também com seis participantes, utilizando-se o mesmo critério, sendo um de mulheres mais jovens (entre 18 e 29 anos) e outro de mulheres mais velhas (com idade acima de 30 anos), totalizando 24 participantes.

\section{Procedimentos para a coleta de dados}

As sessões grupais ocorreram nas dependências do Núcleo de Assistência Médica Integrada (Nami), nas salas do Serviço de Psicologia Aplicada (SPA) da Universidade de Fortaleza (Unifor), onde foram gravadas, estendendo-se, em média, por uma hora e meia, e realizaram-se entre os meses de agosto e dezembro de 2005. Tomando-se como referência as orientações de Gatti (2005), a elaboração do roteiro para o trabalho com o grupo focal foi feita de forma criteriosa, em conformidade com os propósitos da pesquisa. O roteiro de questões para a condução das discussões contemplou três abordagens: 1) a experiência do tempo e a administração das atividades cotidianas; 2 ) a relação entre trânsito, mobilidade urbana e tempo; e 3) os sentimentos e comportamentos relativos à pressa na condução.

Para se lidar com o material obtido, utilizaramse os critérios de uma análise clássica de conteúdo, conforme as orientações fornecidas por Bauer (2002), que partem da ideia de que esse procedimento é uma técnica que produz inferências de um texto focal para seu contexto social de maneira objetiva. Foi tomada ainda como referência a conceituação de Bardin (1979), para quem a análise clássica de conteúdo é um conjunto de técnicas de análise das comunicações que visa produzir, mediante o emprego de procedimentos de descrição do conteúdo das mensagens, indicadores que permitam inferir conhecimentos relativos às condições de sua produção e recepção.

Assim, como sugerem os autores, o tema de pesquisa serviu de guia para a seleção e categorização do material coletado, no caso, as transcrições das discussões grupais em sua totalidade.

\section{Resultados e discussão}

As análises permitiram identificar as categorias e os elementos que emergiram nas conversas, os quais foram agrupados segundo três eixos temáticos: 1) Percepção e administração do tempo; 2) Trânsito, mobilidade urbana e tempo; e 3) Pressa no trânsito.

No primeiro eixo temático - Percepção e administração do tempo - agruparam-se os conteúdos relativos à forma como os participantes percebem a questão do tempo em sua vida, de que modo o administram, como organizam suas atividades e consideram seu ritmo cotidiano, visando compreender melhor o modo como transpõem essa experiência para o ambiente do trânsito.

Reuniram-se, no segundo eixo temático Trânsito, mobilidade urbana e tempo - os conteúdos que abordaram os sentimentos, opiniões e comportamentos relativos ao trânsito e à mobilidade urbana, bem como a relação entre trânsito e tempo na experiência pessoal dos participantes, para a realização das atividades cotidianas: planejamento, horários e tarefas a cumprir.

Buscou-se identificar, no terceiro eixo - Pressa no trânsito -, os conteúdos que abordaram sentimentos, percepções e comportamentos dos participantes nas diversas situações de pressa que se estabelecem para eles no trânsito. Ressaltaram-se, nos discursos, as relações que apresentavam comportamentos inadequados na direção.

Tomando-se como referência o trabalho realizado por Espinosa et al. (1999), objetivou-se descrever os conteúdos relativos a cada eixo temático, apontando-se, em primeiro lugar, os elementos comuns a todos os grupos e, em seguida, aqueles que apareceram apenas em alguns deles. 


\section{Percepção e administração do tempo}

Elementos comuns a todos os grupos

Nesse eixo temático, três questões se fizeram presentes nos discursos de todos os grupos: percepção do tempo, organização do tempo e ritmo de vida.

Acerca da percepção sobre o tempo, os motoristas expressaram a ideia de que ele é sempre insuficiente. Esse sentimento de escassez aparece nas falas, vinculado à percepção de aceleração do tempo. O ritmo de seu transcurso e a sensação de que passa rápido induzem ao sentimento de que ele é sempre insuficiente para tudo o que se intenta realizar, corroborando a afirmação de Santos (2002) de que nossa sociedade se alimenta de tempo e de que somos cronofágicos insaciáveis.

Diversas teorias sobre o tempo identificam essa sensação de aceleração, seja considerando o modo como é experienciada subjetivamente, seja pelas explicações científicas levantadas sobre o fato de que ela não é ilusória, mas teria base real. Nesse sentido, a teoria sobre a Ressonância Schumann, identificada pelo físico alemão W. O. Schumann, afirma que as pulsações eletromagnéticas da Terra se intensificaram a partir dos anos 1980 e, de forma mais acentuada, a partir dos anos 1990, revelando-se nos desequilíbrios ecológicos e sociais do planeta e, inclusive, na aceleração do tempo (Boff, 2004).

Outrossim, a despeito das discussões científicas acerca da questão do tempo, os discursos dos participantes demonstraram que, na sua própria experiência, o ritmo temporal parece cada vez mais acelerado, mesmo que admitam que essa ocorrência decorre de vivências e escolhas individuais e sociais e não necessariamente por questões propriamente físicas ou naturais.

Para todos os participantes mostrou-se importante planejar para organizar o tempo. A boa organização do tempo e a pontualidade pareceram-lhes associadas à eficiência, a qual, a despeito de seus esforços, não conseguem, na maior parte do tempo, alcançar. O sentimento de insatisfação parece estar relacionado à ideia de que, por não conseguirem dominar ou controlar plenamente o tempo, nunca são eficientes o bastante.

Ao falar sobre seu ritmo de vida, muitos participantes dos quatro grupos expressaram que o consideram acelerado, pois precisam desempenhar inúmeras atividades durante o dia. Expressões como sufoco, correria e loucura foram muito utilizadas. Alguns qualificaram seu ritmo como médio e tranquilo. Entretanto, mesmo os participantes aposentados e os estudantes, que não se encontram no mercado de trabalho, apontaram que sempre estão com a agenda cheia e demonstraram a permanente intenção de preencher seu tempo com atividades de algum modo produtivas.

Elementos que emergiram em alguns grupos

Em alguns grupos emergiram elementos como o desejo de preencher o tempo ocioso, a preocupação com a qualidade de vida e a família, o uso de mecanismos para desacelerar e o sentimento de que o tempo é subjetivo.

A preocupação com os efeitos de uma vida estressante para a saúde física e mental, sobretudo para a convivência familiar, foi o elemento que surgiu mais fortemente nos discursos dos grupos de motoristas homens e mulheres com mais de 30 anos, sentimento que não foi identificado nos discursos dos mais jovens. Ficou claro, também, somente no discurso dos mais velhos, a insatisfação com o tempo dedicado ao trabalho, cujo aumento progressivo nem sempre proporciona uma maior renda familiar.

Esses relatos mostram-se em consonância com os diversos estudos que se voltam para a questão do tempo livre e do trabalho, reconhecendo que os tempos predominantes numa sociedade estão estreitamente ligados aos seus modos de produção e às suas formas culturais, a exemplo do de Harvey (1992). Na verdade, retomando-se as colocações de Folkman (1984) e de Lazarus e Folkman (1984), os tempos e os ritmos do trabalho, como causadores de estresse, estão na origem de diversas doenças. Os entrevistados percebem essa realidade mostrando-se capazes de se questionar sobre o seu próprio ritmo de vida e os valores que o condicionam, o que pode se revelar um elemento atenuante dos riscos 
na condução de veículos, na medida em que favoreça a adoção de uma postura menos impulsiva e mais consciente com relação aos próprios atos no trânsito.

Poucos expressaram que investem em medidas para desacelerar o próprio ritmo quando percebem em si mesmos sinais de desequilíbrio ou estresse, o que leva a crer na prevalência, para a maioria, de valores mais pragmáticos de eficiência e de resultados que reafirmam a necessidade de um ritmo intenso de atividades.

Embora o ritmo de vida acelerado tenha sido avaliado pelos participantes de todos os grupos como um aspecto negativo da vida cotidiana na atualidade, o grupo dos mais jovens, bem como o dos homens mais velhos, demonstrou insatisfação ao permanecer com algum tempo ocioso e preocupação expressa de preenchê-lo. Percebe-se, a partir do exposto, que mesmo que se sofra com a falta de tempo, ela é, paradoxalmente, desejada, como elemento de identificação do indivíduo com a maioria, como fator de sua inserção na sociedade e mesmo como indício de qualificação ou aptidão para o mercado de trabalho.

Evidencia-se, aqui, o sentimento de que o tempo tem que ser integralmente ocupado e com algo produtivo, em contraste evidente com a perspectiva das sociedades tradicionais (Oliva-Augusto, 2002), centradas no passado, cujo ideal não impunha sua utilização exaustiva e pragmática. Essa realidade deixa transparecer o embate entre as exigências sociais e os anseios individuais por tempo, o dilema entre a necessidade de desempenho e eficiência tidos como indispensáveis para a sobrevivência em sociedade e as carências individuais de se priorizar tempo livre para encontros e convivência.

É interessante destacar que motoristas homens definiram o tempo como subjetivo, ou seja, que depende do modo como o indivíduo se posiciona diante dele. O comentário de um motorista com mais de 30 anos expressa: "Agora, quanto mais ocupada uma pessoa está, ela sempre tem tempo para fazer alguma coisa". Isso estimulou o outro a dizer: "É, ela sempre tem tempo, exatamente... o tempo é uma coisa subjetiva. Quanto melhor você consegue estar organizado dentro de si, ele sobra". Desse modo, para esses participantes, o fato de ter uma maior quantidade de tarefas a desempenhar não causa, necessariamente, mais dificuldade para lidar com o tempo, podendo desencadear, ao contrário, o acionamento de um mecanismo interno de reação, que estimula o indivíduo a empregar mais esforço pessoal na administração e organização de seu tempo, fazendo-o render mais.

\section{Trânsito, mobilidade urbana e tempo}

Elementos comuns a todos os grupos

Todos os grupos entrevistados mencionaram que o trânsito é um elemento que dificulta o bom uso do tempo, ressaltando sempre o seu aspecto negativo e percebendo-o como um empecilho ao bom desempenho das tarefas cotidianas. Verificou-se na fala de um motorista mais velho que o trânsito é um elemento atrapalhador.

Os entrevistados identificaram como um dos principais empecilhos à fluidez do trânsito o mau desempenho dos outros motoristas. Outros aspectos também foram apontados, como o fato de que a cidade de Fortaleza e sua infraestrutura viária não se adequaram ao crescimento populacional ou, mais especificamente, que as vias da cidade não comportam mais o número de carros que circulam por elas diariamente.

Outra questão considerada relevante foi a das grandes distâncias a serem percorridas que, associadas ao estresse do ambiente do trânsito, tornaram-se fatores de sofrimento para os motoristas. A distância entre o trabalho e a residência foi considerada por eles um dos aspectos importantes para a qualidade de vida.

A fala dos participantes revela claramente a lógica de valores que predomina na contemporaneidade, traduzida na ideia de que o tempo adquiriu uma conotação e um peso de valor produtivo, de que tempo é dinheiro, corroborando os dados do estudo sobre as deseconomias urbanas que estimam os prejuízos financeiros causados pela perda de tempo nos congestionamentos. O estudo mencionado demonstra o quanto esse recurso é hoje considerado um componente valioso 
nos esquemas de produção das sociedades (Ipea, 1998).

Tal sentimento preconiza o ideal moderno, numa perspectiva linear de temporalidade, que aponta sempre para o futuro, para a exigência permanente de eficiência e de resultados. Nesse sentido, os motoristas encaram o ambiente do trânsito como uma etapa a ser rapidamente vencida, sem qualquer valor em si mesma, tendendo a agir nele de forma impulsiva, acelerada, ansiosa, o que acaba por favorecer os comportamentos inadequados à direção.

O sentimento de limitação no ambiente do trânsito também foi muito enfatizado pelos participantes, notadamente quando se encontravam em situações de avanço impedido, em congestionamentos. Isso se pode constatar na fala de uma jovem motorista:

Então o sentimento era esse, do que que eu vou fazer, não posso fazer nada: eu estou aqui, preciso chegar lá, eu estou me atrasando, não vou conseguir e eu posso gritar, posso espernear, posso ficar que nem uma louca e não vou sair daqui! Acho que é aquele sentimento de estar dependendo daquilo ali.

Assim, a sensação de poder proporcionada pelo veículo converte-se, ironicamente, para os entrevistados, numa experiência exatamente oposta, ou seja, de absoluta impotência. Para fazer frente a essas circunstâncias do trânsito, os motoristas reconhecem que é imprescindível planejar e organizar o tempo dos deslocamentos diários para se atingir o grau de eficiência esperado ou exigido do cidadão moderno. Entretanto, para eles, os frequentes insucessos com relação ao bom planejamento do dia a dia levam a crer que mesmo as pessoas com estilo de vida mais organizado e que conseguem programar suas atividades não estão isentas de verem frustrado seu plano e de reagir mal à direção diante das situações imprevistas no trânsito.

Pelo que se pôde perceber no relato de alguns participantes, em todos os grupos, o fato de terem feito um planejamento e vê-lo frustrado, por motivos aos quais não deram causa, pode provocar uma sensação de maior irritação para eles do que para aqueles que não investiram numa programação prévia. Embora não se possa afirmar que esses motoristas têm reações comportamentais negativas diante dos imprevistos, percebe-se, pelo seu relato, que a sensação de insatisfação e irritação no trânsito pode se tornar mais intensa para esses indivíduos comedidos do que para aqueles naturalmente mais impulsivos e pouco organizados. A fala de uma jovem motorista revela essa disposição:

Eu sou muito de planejar, porque se eu planejo alguma coisa então eu vou tentar cumprir daquela forma que eu planejei, mas se alguma coisa dá errado, assim, não porque eu tenha feito, e não dá para ser do jeito que eu planejei, aí já fica tudo confuso para mim, eu já não sei mais o que fazer.

As circunstâncias apontadas nessas falas indicam que o planejamento e a organização do tempo entram como elementos cruciais na administração do cotidiano das pessoas, em face de um esquema de vida excessivamente cronometrado e voltado para a divisão e fragmentação do tempo, sob pena de fracasso na realização dos seus objetivos. Ainda assim, independentemente do empenho em planejar, as estruturas temporais predominantes num dado grupo social, com todos os seus elementos complicadores, notadamente os empecilhos do trânsito, acabam interferindo decisivamente nos esquemas temporais individuais. Assim, o permanente embate entre os tempos individuais e os tempos sociais se torna decisivo para a constituição do ambiente do trânsito.

Outra forma apontada para se fazer frente às frustrações do ambiente do trânsito foi a atitude de autocontrole diante da impossibilidade de se cumprir o trajeto no tempo esperado. Se alguma situação imprevista dificulta ou bloqueia o percurso, impedindo a realização da atividade pretendida, alguns motoristas acabam por reconhecer a própria impotência diante da situação. Buscam adequar-se a essa realidade, adaptando-se e aceitando os limites ou os bloqueios de mobilidade gerados por eventuais imprevistos ocorridos durante $\mathrm{o}$ trajeto no trânsito.

Esse seria, também, um mecanismo de defesa pelo qual os indivíduos, como ressaltou Foucault (1993), realizam, por meio da disciplina, o ajustamento do corpo a imperativos espaciais e temporais e o controle sobre os corpos a 
partir do controle de horários. Nesse sentido, as necessidades individuais de tempo acabam se ajustando às imposições temporais do trânsito, podendo tornar essa experiência um fator atenuante dos riscos à direção.

Elementos que emergiram em alguns grupos

Foi identificado em mulheres mais velhas o sentimento de que o tempo de permanência no veículo, durante os trajetos, é tido não somente como tempo perdido mas também como uma ocasião para se estar só, um momento de privacidade, que pode ser usufruído sem a pressão oferecida pela presença de filhos, marido e tensões do dia a dia. Nesse sentido, pode-se inferir que a agitação da vida cotidiana vivida por muitos participantes dos grupos não deixa que sobre tempo para os momentos de solidão, de autoconfrontação, de relaxamento considerados tão necessários ao equilíbrio emocional do indivíduo.

Paradoxalmente, em meio à agitação das atividades, mais especificamente durante os deslocamentos no trânsito, essas pessoas parecem viver uma experiência singular. Ao mesmo tempo em que criam um mecanismo de autodefesa contra as insatisfações e empecilhos do trânsito, satisfazem uma necessidade que certamente não é atendida suficientemente em meio ao ritmo de vida acelerado que experimentam, qual seja, a necessidade de tempo para si mesmas, de isolamento e liberdade. Uma motorista com mais de 30 anos revela: "Eu adoro dirigir, vou pegar meu carro, botar meu som, não vai ter menino, marido, nem ninguém para mandar em mim... [risos]. Aí é um relaxamento!"

O tempo de permanência no trânsito também foi apontado como um momento para se ouvir música, comentário ausente apenas nos discursos dos homens mais velhos, embora surgisse espontaneamente nas conversas das mulheres e dos homens mais jovens. Essa experiência indica que a música durante a direção pode surtir um efeito terapêutico, minimizando a angústia do tempo despendido, o que pode ocorrer tanto em situações rotineiras de espera ou automatizadas, no trânsito, quanto em momentos de estresse intenso, de avanço impedido, para relaxar e defender-se dessa limitação. Assim, tal circunstância tanto pode se tornar atenuante de risco, por liberar estresses e tensões, quanto um agravante, por favorecer os desvios de atenção à direção.

Um dos comentários que emergiu apenas nos relatos das mulheres é que o ato de dirigir muitas vezes é feito automaticamente. Essa experiência foi citada por uma senhora:

Às vezes você tá aqui dirigindo, eu não sei, acho que com todo mundo já aconteceu, você tá com o pensamento tão longe... com as coisas que você tem que fazer, que às vezes você se toca: Valha-me Deus, eu tô dirigindo!

Dirigindo de forma automática os motoristas não atentam, muitas vezes, para as situações imprevistas que acontecem no trânsito, cometendo à direção atos ligados à falta de atenção, como errar o percurso ou frear de forma brusca. Ao descrever os processos psíquicos básicos do comportamento no trânsito, Rozestraten (1988) menciona a questão da percepção e da tomada de informações do motorista, o qual deve estar permanentemente em vigilância ou atenção difusa, que permite manter um estado de alerta para indícios de perigo. Nas condições descritas, os motoristas ficam sujeitos a apresentar algum comportamento inadequado à direção por desequilíbrio no processo apontado. Ressaltase, aqui, a relação desse dado com aquele fornecido por Macêdo (2004), que informa que as mulheres e os motoristas mais velhos relatam, com mais frequência, comportamentos envolvendo problemas de atenção e de memória, possivelmente relacionados a esses automatismos no trânsito.

Foi curioso perceber, no relato de alguns, a experiência contraditória de que uma maior distância a ser percorrida implica, muitas vezes, mais pontualidade dos motoristas. $\mathrm{Na}$ verdade, a maior distância exige um melhor planejamento, o que implica, frequentemente, maior eficiência no cumprimento dos horários. Quando a distância é mínima, ao contrário, o motorista é induzido a um relaxamento, o que, muitas vezes, faz com que ocorra o atraso. Encontrou-se esse dado tanto nas falas das moças quanto nas dos rapazes. Uma jovem relata: 
Uma outra coisa que eu percebo é que quanto mais longe é o lugar mais eu me preocupo, assim... se eu me atrasar e tal. Por exemplo, tem uma igrejinha vizinha à minha casa, eu e minha mãe, a gente sempre chega cinco minutos atrasadas.

\section{Pressa no trânsito}

Elementos comuns a todos os grupos

As falas dos motoristas revelaram que o ritmo de vida acelerado característico da sociedade induz naturalmente a uma sensação de pressa contínua, levando à impressão, muitas vezes falsa, de que há um horário a cumprir. Assim, a sensação de pressa é frequentemente internalizada pelos motoristas que, impregnados por um estado de urgência, sentem que nunca há tempo a perder. Isso foi claramente expresso na fala de uma motorista mais velha: "Todos ao redor estão com pressa, não necessariamente a gente, tudo é apressado, a evolução da tecnologia é rápida, tudo é rápido, então a gente tem a sensação de que também tá apressado".

Rozestraten (1988), ao descrever os processos psíquicos básicos do comportamento no trânsito, observa que, após a captação das informações oriundas do ambiente do trânsito, seu processamento e a decisão, vem a reação ou o comportamento observável do motorista. Esse comportamento, muitas vezes, não provém de uma informação adequada, mas de condicionamentos e automatismos adquiridos pelo motorista ao longo de seu tempo como condutor, situações em que pode parecer que não há tempo entre o estímulo e a resposta, como pode ocorrer no caso da pressa internalizada. Nessas condições, num pequeno intervalo de tempo é possível acontecer um acidente, pois qualquer falha nessa sequência de processos poderá ser fatal.

É importante, também, ressaltar que o estado subjetivo dos motoristas influencia sua percepção do tempo. Em situações de pressa, eles disseram experimentar um sentimento de que tudo acontece para impedir a boa fluidez do tráfego, o que intensifica a sensação de angústia. Qualquer empecilho que ocorre no trânsito adquire maior intensidade e surte um efeito mais angustiante do que quando fora das situações de pressa. É o que se pode constatar ante a fala desse jovem motorista: "Começa que quando você tá com pressa tudo dá errado, né? Sempre tem um 'lesado' acompanhando".

Essas experiências podem ser compreendidas à luz da ideia de Ades (2002), segundo a qual o tempo não é uma dimensão fria de pura constatação, mas é carregado da experiência subjetiva. Como até o senso comum reconhece: "Quando observada, a panela não ferve!" Constata-se, de fato, não só aqui como em outras situações apontadas nos relatos dos participantes dos grupos, esse aspecto curioso da vivência psicológica do tempo que consiste, no dizer de Ades (2002), na possibilidade de esticar-se ou comprimir-se de acordo com o contexto, em aparente desrespeito ao tempo do relógio. Na verdade, o estado de ansiedade dos motoristas é capaz de modificar totalmente sua experiência do tempo, vindo a favorecer as situações de risco e eventuais erros e violações à direção.

Todos os grupos mencionaram adotar mecanismos imprevistos para driblar os engarrafamentos e empecilhos à livre fluidez do tráfego e ganhar tempo, o que pode gerar comportamentos impulsivos e inadequados. Um motorista mais velho expressa: "Agora eu tenho buscado mecanismos, um dia desses eu descobri um... [caminho]. O meu passatempo agora é esse, é buscar alternativas no trânsito".

O ato de sair com bastante antecedência para não sofrer a perda de tempo nos horários mais congestionados também foi mencionado e gera, sem dúvida, uma situação atenuante de riscos e de cometimento de erros e violações no trânsito.

A ansiedade, a raiva, a irritação, o medo, a tensão, o desespero, a sensação de impotência, a revolta foram os sentimentos apontados pelos motoristas associados à pressa na direção e ao progresso impedido. Uma motorista mais jovem expressou: "Menina, eu tinha vontade de sair do carro, tinha hora que eu parava o carro, eu saía, puxava o cabelo..." O grupo dos rapazes também se manifestou: "Dá vontade de sumir com os carros da frente, assim..." E, ainda: "Dá vontade de desaparecer..." E outro: "Dá vontade de voar". 
O sentido de urgência vivido nessas situações parece induzir comportamentos impulsivos ou até agressivos por parte dos motoristas, conforme se pode verificar no discurso de um dos participantes mais velhos: "[...] o que vier na minha cabeça eu digo, eu grito, às vezes esmurro a direção, com raiva, sou neurótico urbano assumido".

Em todos os grupos, alguns participantes afirmaram que o sentimento nas situações de pressa está em função da natureza do compromisso. Caso seja considerado realmente importante, como ocorre em circunstâncias envolvendo o trabalho, os empecilhos se tornam mais angustiantes. Como observa Rozestraten (1988), adentrando o campo da motivação humana no trânsito, é a escala de valores e o julgamento sobre qual desses valores é o mais importante que vão orientar sua decisão. Uma participante mais velha também se manifestou sobre a sua experiência de pressa: "No trânsito, o que tem de mais forte é isso, é essa ansiedade, né? E quando chega no nível da irritação... você sai fazendo doidice". Outra revelou: "Eu estava atrasada pra aula da minha filha... eu superatrasada, eu peguei aquela rua... aumenta a adrenalina, você não tem medo de nada!"

Rozestraten (1988) também reconhece que, às vezes, as pessoas decidem assumir riscos maiores do que aqueles que aceitam normalmente porque estão com pressa e o prejuízo de um atraso seria grande. De fato, alguns participantes afirmaram expressamente que ficam totalmente modificados em situações de pressa. Uma jovem comenta:

Eu acho engraçado como é que a pressa me modifica... pelo menos comigo... assim.... eu fico totalmente diferente quando eu tô apressada. E quando eutô apressada aí é que eu uso mesmo a buzina.

Assim, os relatos expressaram o quanto a situação de pressa altera o estado emocional do motorista. Ao falarem dos seus comportamentos no trânsito, relatam que essas situações os induzem, muitas vezes, a terem atitudes que não aprovam e não tomariam se não estivessem numa situação de escassez de tempo. Alguns integrantes de todos os grupos afirmaram não cometer infrações graves, mesmo nas situações de pressa, embora admitam cometer infrações mais leves.
Elementos que emergiram em alguns grupos

Apenas nos grupos mais jovens, masculino e feminino, pôde-se identificar um caráter de competição nas atitudes adotadas no ambiente do trânsito, notadamente quando em situações de pressa. Embora o espírito competitivo tenha surgido também entre as jovens, os rapazes deram mais ênfase a esse sentimento, revelado também a partir das situações de hostilidade e dos atritos com outros motoristas. Como explicita Rozestraten (1988), o ambiente do trânsito é multifatorial e potencialmente propício a conflitos, o que acaba exigindo dos atores nele envolvidos um esforço adicional para administrá-los.

Destaca-se, aqui, o estudo realizado por MarínLeón e Vizzotto (2003) sobre o comportamento de estudantes universitários no trânsito, no qual se revela que os jovens, especialmente os do sexo masculino, constituem o grupo com maior envolvimento em acidentes fatais. As atitudes presentes nesta pesquisa vão ao encontro dos resultados do trabalho em comento. Como se vê, atitudes típicas da juventude, afeita à competição e à impulsividade, são potencialmente favorecedoras de comportamentos inadequados à direção.

A fala dos mais velhos se contrapõe frontalmente à dos mais novos, reforçando a percepção de que a idade é um elemento decisivo para o comportamento no trânsito. Uma motorista mais velha relata que, mesmo com pressa, não comete infrações. De modo geral, percebese que esses participantes apresentaram um discurso mais moralista, no sentido de se autoatribuírem comportamentos socialmente corretos ou, pelo menos, de defendê-los com ênfase.

Com efeito, Parker, Reason, Manstead e Stradling (1995) afirmam que o relato do cometimento de violações está associado a jovens do sexo masculino, que se estimaram como melhores motoristas e possuíam alta quilometragem anual. Os homens relatam cometer mais violações que as mulheres, mas, quanto mais jovens, maior a probabilidade de relatarem o cometimento de violações em relação aos mais velhos. 


\section{Conclusão}

Os resultados obtidos neste trabalho levam a concluir que as questões relativas ao tempo e à pressa exercem relevante influência na experiência dos motoristas, afetando seu estado emocional, constituindo elementos motivadores para o cometimento de erros e violações no trânsito.

Os dados apresentados nos discursos, quando não expressam ações concretas no trânsito, indicam tendências de ação, ao revelar sentimentos, opiniões e posturas dos motoristas perante a questão estudada. As informações que emergiram possibilitaram compreender melhor suas atitudes e comportamentos, a dinâmica do trânsito, e, em última instância, o ambiente urbano no qual estão inseridos.

Não foram observadas grandes divergências entre os resultados aqui obtidos e aqueles apresentados em outros estudos abordando as situações de trânsito em geral. Nessa perspectiva, pode-se inferir que as questões do tempo e da pressa encontram-se de tal maneira incorporadas à experiência do cidadão moderno que se torna muito difícil distinguir, com precisão, situações determinadas por esses elementos de forma isolada.

Entretanto, mesmo não tendo indicado vinculações de causa e efeito de caráter absoluto ou necessário entre as questões do tempo e da pressa e os comportamentos inadequados na direção, esta pesquisa atingiu os objetivos a que se propôs, pois foi capaz de identificar experiências subjetivas e comportamentos dos motoristas associados ao tempo e à pressa, apresentando importantes elementos que compõem essa relação.

Admitir, ao mesmo tempo, que tais experiências tenham uma dimensão subjetiva implica atribuir também às pessoas envolvidas a responsabilidade por sua constituição. Significa retomar a ideia, já comentada, de que o motorista, ao tempo em que sofre as inúmeras determinações do mundo externo, inclusive das exigências de tempo que o condicionam, age ativamente para constituir essa superestrutura que acaba por submetê-lo e ultrapassá-lo.
Como se conjugam as exigências sociais de cidadania e as manifestações da subjetividade humana no ambiente do trânsito? Que indivíduo é esse que compõe, constrói e determina esse ambiente? De que forma as manifestações da individualidade e dos interesses particulares, inclusive de tempo, determinam o caráter hostil, egoístico, mortífero do trânsito, cerceando o espaço público, lugar que originalmente seria território do encontro com o outro?

Com efeito, as questões relativas ao trânsito e ao ambiente urbano como um todo inevitavelmente remetem a uma perspectiva do indivíduo enquanto componente preponderante e principal gerador de atitudes e comportamentos nesse lugar. Todavia não se pode desconsiderar todo o contexto que envolve essa realidade. Como foi possível observar, o crescimento da população urbana e da frota de veículos tende a agravar a situação do trânsito. Assim se vive o grande desafio de acomodar, com qualidade e eficiência, essa população adicional e os deslocamentos que se necessita fazer, uma vez que o aumento da frota de automóveis tende a agravar os problemas de congestionamentos e poluição.

Verificou-se, ainda, que as preocupações dos técnicos e autoridades têm se voltado a contínuas ampliações do sistema viário, frequentemente a custos muito elevados, priorizando o automóvel, o que tem levado à violação de áreas residenciais e coletivas, bem como à degradação do patrimônio histórico e arquitetônico, além de consumir recursos que poderiam, em muitos casos, ser investidos na melhoria de condições do transporte público.

No exercício democrático de seus direitos é pertinente e legítima a participação da sociedade nas discussões e ações referentes ao trânsito. A movimentação da coletividade tentando organizar-se, induz os governos a, paulatinamente, abrir espaços e oportunidades à participação.

Almeja-se lançar luz sobre essa problemática, apontando questionamentos e estudos que possam preencher lacunas e ampliar os elementos abordados por este trabalho e, assim, contribuir para a construção de um ambiente favorável à implantação de uma cultura orientada ao exercício do trânsito cidadão e da qualidade de vida. 


\section{Ana Inez Oka Elvas de Lima}

Mestre em Psicologia pela Universidade de Fortaleza, Fortaleza - CE. Brasil.

E-mail: aninhaoka@gmail.com

\section{Sylvia Cavalcante}

Universidade de Fortaleza, Fortaleza - CE. Brasil.

E-mail: sylviac@unifor.br

Endereço para envio de correspondência:

Rua Desembargador Waldemar Pereira, 315, Casa 3. Luciano Cavalcante. CEP 60810-700

- Fortaleza, CE - Brasil.

Recebido 17/02/2013, Aprovado 03/10/2014. 
Ades, C. (2002). A experiência psicológica da duração. Revista Ciência e Cultura, 54(2), 26-29.

Bardin, L. (1979). Análise de conteúdo. Lisboa: Edições 70.

Bauer, M. W. (2002). Análise de conteúdo clássica: uma revisão. In M. W. Bauer \& G. Gaskell (Eds.), Pesquisa qualitativa com texto, imagem e som: um manual prático (pp. 189-217). Petrópolis: Vozes.

Boff, L. (2004, Março 05). Ressonância Schumann. Jornal O Povo, p. 33.

Brasil. Ministério das Cidades. Departamento Nacional de Trânsito. (2004). Diretrizes para a Política Nacional de Trânsito. Brasília.

Carlini-Cotrim, B. (1996). Potencialidades da técnica qualitative grupo focal em investigações sobre abuso de substâncias. Revista de Saude Publica, 30(3), 285-293. http://dx.doi.org/10.1590/ S0034-89101996000300013. PMid:9110476

Departamento Estadual de Trânsito do Ceará DETRAN-CE. (2010). Estatísticas: evolução da frota 1980-2010. Recuperado em 10 de fevereiro de 2013, de http://www.detran.ce.gov. br/site/arquivos/ estatisticas/Veículos/2010/ CRESCIMENTO\%20DA\%20FROTA\%20-\%20 1980-2010.pdf

Espinosa, A. G., Díaz, E. M., \& Aravena, J. P. V. (1999). Exploración del discurso acerca de la seguridad de tránsito en usuários de vias em Santiago de Chile. In E. M. Diaz (Ed.), Psicologia Social y seguridad de tránsito (pp. 61-86). Santiago: Editorial Universidad de Santiago.

Folkman, S. (1984). Personal control and stress and coping processes: a theoretical analysis. Journal of Personality and Social Psychology, 46(4), 839-852. http://dx.doi.org/10.1037/00223514.46.4.839. PMid:6737195

Foucault, M. (1993). Vigiar e punir. Petrópolis: Vozes.

Gaskell, G. (2002). Entrevistas individuais e grupais. In M. W. Bauer \& G. Gaskell (Eds.), Pesquisa qualitativa com texto, imagem e som: um manual prático (pp. 64-89). Petrópolis: Vozes.

Gatti, B. A. (2005). Grupo focal na pesquisa em Ciências Sociais e Humanas. Brasília: Liber Livro.

Günther, H. (2004). Pesquisa qualitativa versus pesquisa quantitativa: esta é a questão? (Planejamento de Pesquisa nas Ciências Sociais, No. 7). Brasília: UnB.
Harvey, D. (1992). A condição Pós-moderna. São Paulo: Loyola.

Instituto Brasileiro de Geografia e Estatística - IBGE. (2010). Recuperado em 10 de fevereiro de 2013, de http://www.ibge.gov.br/cidadesat/ topwindow.htm?1

Instituto de Pesquisas Econômicas Aplicadas - Ipea. Associação Nacional de Transportes Públicos. (1998). Redução das deseconomias urbanas com a melhoria do transporte público. Brasília.

Lazarus, R. S., \& Folkman, S. (1984). Stress, appraisal and coping. New York: Springer.

Macêdo, G. M. (2004). Estudo das relações entre o nível de habilidade e direção segura, a irritabilidade e o cometimento de violações e erros do motorista e seu possível envolvimento em acidentes de trânsito. Tese de Doutorado, Instituto de Psicologia, Universidade de São Paulo, São Paulo, SP.

Marín-León, L., \& Vizzotto, M. M. (2003). Comportamentos no trânsito: um estudo epidemiológico com estudantes universitários. Cadernos de Saude Publica, 19(2), 515-523. http:// dx.doi.org/10.1590/S0102-311X2003000200018. PMid:12764467

Mello, K. R. C. (1998). Transporte urbano de passageiros: as contradições do poder público. Tese de Doutorado, Departamento de Geografia, Faculdade de Filosofia, Letras e Ciências Humanas, Universidade de São Paulo, São Paulo, SP.

Monteiro, C. A. S. (2004). Variáveis antecedentes de erros e violações de motoristas. Tese de Doutorado, Instituto de Psicologia, Universidade de Brasília, Brasília, DF.

Oliva-Augusto, M. H. (2002). Tempo, indivíduo e vida social. Revista Ciência e Cultura, 54(2), 30-33.

Parker, D., Reason, J., Manstead, A., \& Stradling, S. (1995). Driving errors, driving violations and accidents involvement. Ergonomics, 38(5), 1036-1048. http://dx.doi. org/10.1080/00140139508925170.

Rozestraten, R. J. A. (1988). Psicologia do trânsito: conceitos e processos básicos. São Paulo: EDU/EDUSP.

Santos, M. (2002). O tempo nas cidades. Revista Ciência e Cultura, 54(2), 21-22. 
Errata Na edição 35.1, no artigo "Tempo e Trânsito na Experiência subjetiva de motoristas", a filiação principal da autora Sylvia Cavalcante é Universidade de Fortaleza e não Université Louis Pasteur. http://dx.doi.org/10.1590/1982-3703000412013 